\title{
Mediastinal Extraskeletal Osteosarcoma in a Canine with Pulmonary and Cerebral Metastasis
}

\author{
Taina dos Santos Alberti', Rosimeri Zamboni', Fabiano da Rosa Venancio', Carolina Buss Bruner', \\ Margarida Buss Raffi', Ana Lucia Schild² \& Eliza Simone Viégas Sallis'
}

\begin{abstract}
ABSTRAT
Background: Extraskeletal osteosarcoma (EOS), a rare variant of osteosarcoma (OS), is a malignant neoplasm that develops in soft tissues without primary bone involvement. This study aims to describe a case of EOS with a mediastinal location in a canine. Case: A 10-year-old male Uruguayan Cimarron dog, was presented to the Laboratório Regional de Diagnóstico, Faculdade de Veterinária, Universidade Federal de Pelotas (LRD/FV/UFPel) for necropsy. The dog had a history of submandibular swelling, progressive hind limb paralysis, muscle atrophy, and breathing difficulties. During necropsy, in the thoracic cavity, approximately $900 \mathrm{~mL}$ of serosanguinous exudate and a reddish-brown, bossed mediastinal mass measuring $15.0 \mathrm{~cm}$ in the longest axis were also noted. The lung exhibited multifocal to coalescent, white, firm nodules extending from the pleura to the parenchyma and measuring up to $4.5 \mathrm{~cm}$ in diameter. In the parietal and occipital region of the brain, a matte wine mass measuring $2.3 \mathrm{~cm}$ in the longest axis was observed. Fragments of the neoplastic mass, organs of the abdominal and thoracic cavities, and the brain were harvested and fixed in $10 \%$ buffered formalin. After $48 \mathrm{~h}$, the samples were routinely processed, incorporated in paraffin, cut into $3 \mu \mathrm{m}$-thick sections, and stained using Hematoxylin and Eosin (HE). Selected sections of the neoplasm, the lung, and the brain were subjected to Von Kossa staining and immunohistochemical (IHC) analysis. For IHC, primary anti-cytokeratin monoclonal antibodies (clone AE1 / AE3, BioCare Medical) at a 1:100 dilution, vimentin (clone V9, BioCare Medical) at a 1:100 dilution, S100 Protein (clone 15E2E2, BioCare Medical) at a 1:100 dilution, and Ki67 (SP6 clone, BioCare Medical) at a 1:50 dilution were used. Immunostaining was visualized using 3-3' diaminabenzidine (DAB). Histological evaluation of the mediastinal mass, the pulmonary nodules, and the central nervous system among polygonal mesenchymal cells was conducted. Marked pleomorphism with euchromatic, rounded to oval nuclei, evident nucleoli, and poorly delimited eosinophilic cytoplasm. Neoplastic cells were arranged in nests and bundles with an invasive growth pattern. Osteoid and bone matrix formation as well as multinucleated giant cells of the osteoclast type were observed. The bone matrix was better evidenced in Von Kossa staining. IHC in all analyzed sections of the neoplastic cells showed positive immunostaining for Vimentin and Ki67. In the sections incubated with anti-cytokeratin and S100 protein antibodies showed no presence of neoplastic cells.

Discussion: The diagnosis of EOS was based on the absence of primary bone lesions during microscopic necroscopy and on the exclusion of other histogenetic origins using IHC. The absence of primary bone lesions was the main attribute that differentiates EOS from other variants osteosarcomas, such as central/medullary and surface OS (periosteal and paraosteal) most frequently in canine species. The origin of EOS is uncertain. However, its occurrence has been originated with in pluripotent cells or previous injuries, such as retention of surgical sponges and vaccination sites. In this case, since the animal had no clinical history of injuries or surgical procedures that could induce the formation of a mediastinal neoplasm, the probable origin of the neoplasm was pluripotent cells. In dogs, EOS occurs mainly in the mammary glands, digestive system, liver, spleen, and subcutaneous tissue. Furthermore, the mediastinal location observed in this study was described only in goats. The clinical signs are nonspecific and varies with the location of the tumor, as observed in the present report. EOS may also present mediastinal location in the canine species. Necropsy, histopathological examination, and IHC were essential to establish the diagnosis of this OS variant.
\end{abstract}

Keywords: osteosarcoma, mesenchymal neoplasm, mediastinal tumor.

DOI: $10.22456 / 1679-9216.109709$

${ }^{1}$ Departamento de Patologia Animal \& ${ }^{2}$ Laboratório Regional de Diagnóstico (LRD), Faculdade de Veterinária, Universidade Federal de Pelotas (UFPel), Capão do Leão, RS, Brazil. CORRESPONDENCE: T.S. Alberti [taina_alberti@yahoo.com] \& R. Zamboni [rosi_zamboni@yahoo.com.br]. Campus Universitário s/n. CEP 96010-900 Capão do Leão, RS, Brazil. 


\section{INTRODUCTION}

Extraskeletal osteosarcomas (EOS) are malignant neoplasms of mesenchymal origin and are characterized by the production of osteoid. They develop in soft tissues without primary bone involvement, representing a rare variant of osteosarcoma (OS) in all species. In dogs, it corresponds to $<1 \%$ of OS diagnoses $[13,16]$.

EOS are locally invasive and highly metastatic neoplasms, with lung metastasis occurring in $90 \%$ of cases. The prognosis is unfavorable with an average survival of 2 months after diagnosis $[2,4,6,10]$. The aim of this study was to report a case of EOS with a mediastinal location in a canine.

\section{CASE}

A 10-year-old male Uruguayan Cimarron dog, was referred to the Laboratório Regional de Diagnóstico, Faculdade de Veterinária, Universidade Federal de Pelotas (LRD/FV/UFPel) for necropsy. The dog had a history of submandibular swelling, progressive hind limb paralysis, muscle atrophy, and breathing difficulties.

During necropsy, marked subcutaneous edema was observed in the submandibular region and the thoracic limbs. In the thoracic cavity, approximately 900 $\mathrm{mL}$ of serosanguinous exudate and a reddish-brown, bossed mediastinal mass measuring $15.0 \mathrm{~cm}$ in the longest axis were also noted. When cut, the tumor was white, lobulated, with yellowish necrotic regions and with firm to ebony areas. The lung exhibited multifocal to coalescent, white, firm nodules extending from the pleura to the parenchyma and measuring up to $4.5 \mathrm{~cm}$ in diameter (Figure 1A). In the parietal and occipital region of the brain, a matte wine mass measuring 2.3 $\mathrm{cm}$ in the longest axis was observed (Figure 1B).

Fragments of the neoplastic mass, organs of the abdominal and thoracic cavities, and the brain were harvested and fixed in $10 \%$ buffered formalin. After $48 \mathrm{~h}$, the samples were routinely processed, incorporated in paraffin ${ }^{1}$, cut into $3 \mu \mathrm{m}$-thick sections, and stained using Hematoxylin and Eosin $(\mathrm{HE})^{2}$. Selected sections of the neoplasm, the lung, and the brain were subjected to Von Kossa ${ }^{3}$ staining and immunohistochemical (IHC) analysis. For IHC it were used: primary anti-cytokeratin ${ }^{4}$ monoclonal antibodies (clone AE1 / AE3) at a 1:100 dilution, vimentin (clone V9) at a 1:100 dilution, S100 Protein ${ }^{4}$ (clone 15E2E2) at a 1:100 dilution, and $\mathrm{Ki}^{4} 7^{4}$ (clone SP6) at a 1:50 dilution. Im- munostaining was visualized using 3-3' diaminabenzidine $(\mathrm{DAB})^{5}$. The sections were counterstained with Harris hematoxylin ${ }^{2}$. As a negative control for each case, a section of the analyzed tissue was incubated only with the antibody diluent, Phosphate Buffered Saline (PBS) ${ }^{4}$.

Histological evaluation of the mediastinal mass, the pulmonary nodules, and the central nervous system among polygonal mesenchymal cells was conducted. Marked pleomorphism with euchromatic, rounded to oval nuclei, evident nucleoli, and poorly delimited eosinophilic cytoplasm were observed. In addition, 3-4 mitotic figures per field with the highest magnification (40x) were also noted. Neoplastic cells were arranged in nests and bundles with an invasive growth pattern. Osteoid and bone matrix formation as well as multinucleated giant cells of the osteoclast type were observed. Neoplastic emboli in the lymphatic vessels, areas of necrosis, and hemorrhage were also observed (Figure 2A and 2B).

IHC in all analyzed sections of the neoplastic cells showed positive immunostaining for Vimentin and Ki67 (Figure 3A and 3B), with Ki67 showing strong positive markings of osteoclastic giant cells. In contrast, sections incubated with anti-cytokeratin and $\mathrm{S} 100$ protein antibodies showed no presence of neoplastic cells (Figure 3C and 3D).

\section{DISCUSSION}

In this report, the diagnosis of EOS was based on the absence of primary bone lesions during microscopic necroscopy and on the exclusion of other histogenetic origins using IHC. The absence of primary bone lesions is the main attribute that differentiates EOS from frequently occurring osteosarcomas, such as central/medullary and surface OS (periosteal and paraosteal) [16]. Furthermore, nuclear scintigraphy, whole body radiography, and/or necropsy are the main diagnostic tools used to investigate the presence of bone lesions in suspected cases of EOS $[14,16]$.

Central and surface OS occur mainly in the appendicular skeleton and are more prevalent in large and giant canine breeds [16]. This prevalence is related to the high mitotic activity of the metaphyseal growth plate and to bone cell mutations secondary to traumatic events due to high regional impact $[4,16]$. The origin of EOS is uncertain. However, in some cases, its occurrence has been associated with previous injuries, 


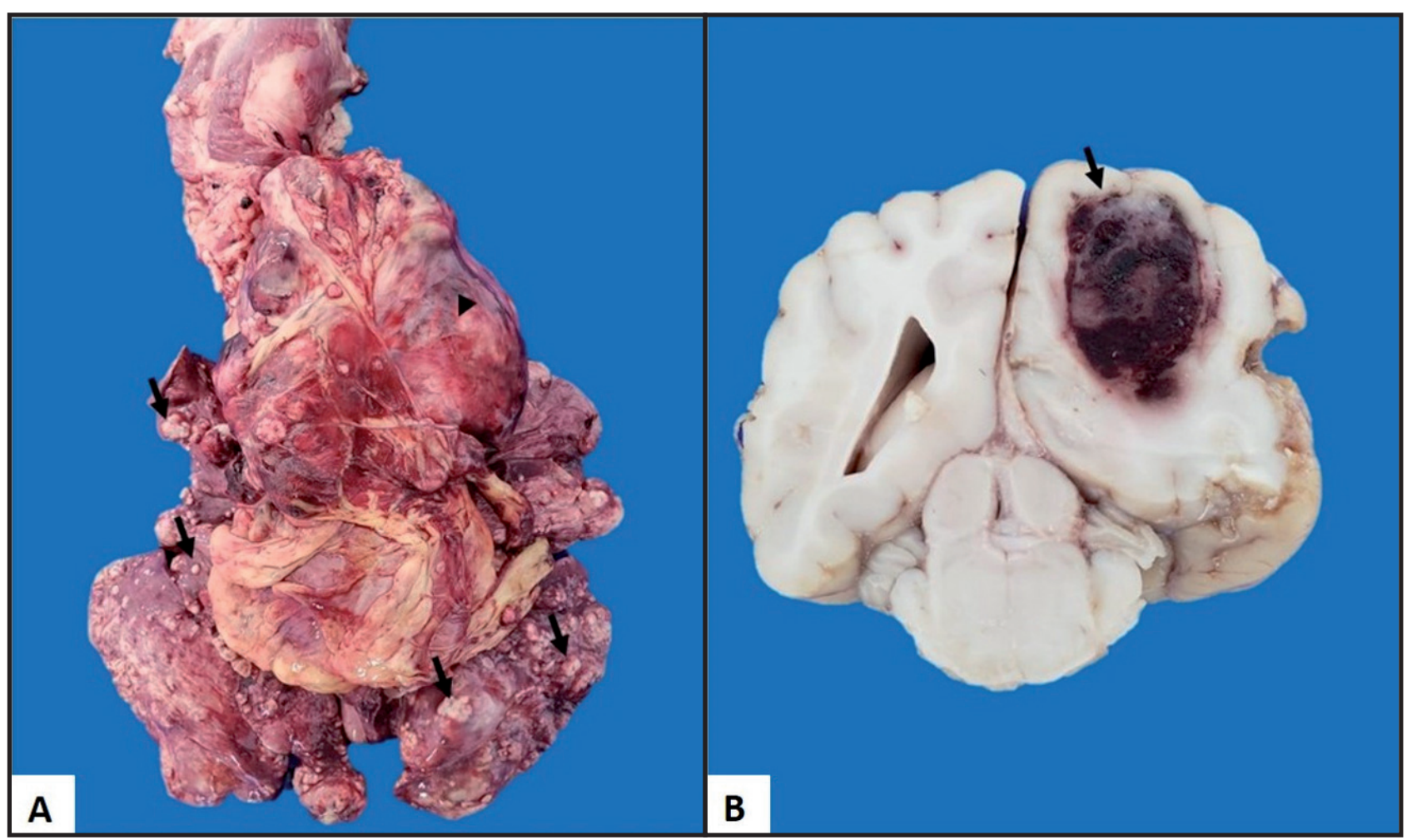

Figure 1. Metastases extraskeletal osteosarcoma in a dog. A- Lung with white, multifocal nodules on the pleural surface (arrow) and a large mediastinal mass with a reddish-white, bossed surface (arrowhead). B- Brain with wine and matte area in the region of the parietal and occipital cortex.

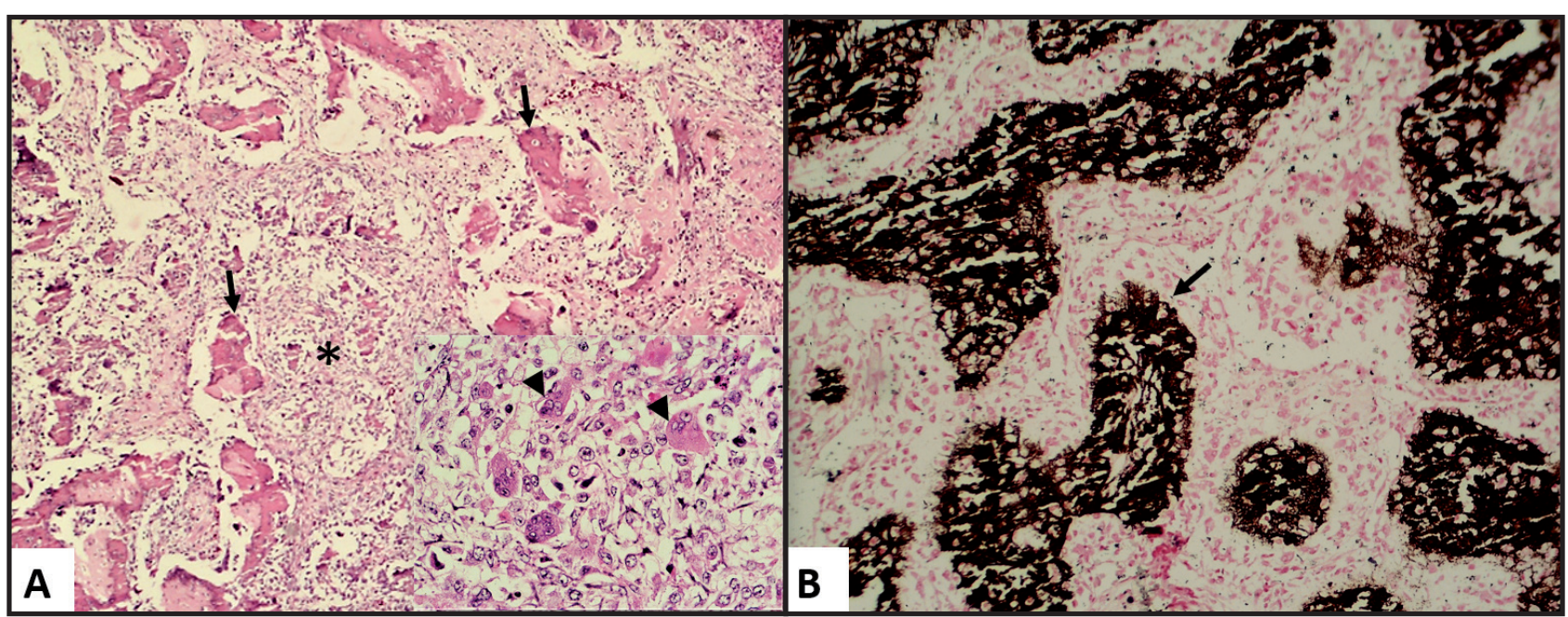

Figure 2. Histopathology of extraskeletal osteosarcoma in a dog. A- Mediastinal neoplasm with cellular proliferation (*) and large amounts of bone trabeculae (arrow) [HE; 4x]. Giant osteoclast cells (arrow) in the middle of pleomorphic and polygonal cells [HE; 40x]. B- Von Kossa staining showing the bone matrix $[10 x]$.

such as retention of surgical sponges and vaccination sites $[12,14]$. In contrast, EOS can still originate in pluripotent cells. In many cases, the location of its occurrence is not related to previous lesions [11]. In this case, since the animal had no clinical history of injuries or surgical procedures that could induce the formation of a mediastinal neoplasm, the probable origin of the neoplasm was pluripotent cells.
The highest occurrence of EOS is observed in Beagles and Rottweilers, with no predisposition for large and giant animals as observed in other OS variants $[4,6,9]$. Predisposition by sex is not observed in canines; however, studies that include OS of the mammary gland point to a higher occurrence in females than in males [8]. Additionally, the animal in the present case was also within the age group (10.4 years) more predisposed to developing EOS [8]. 


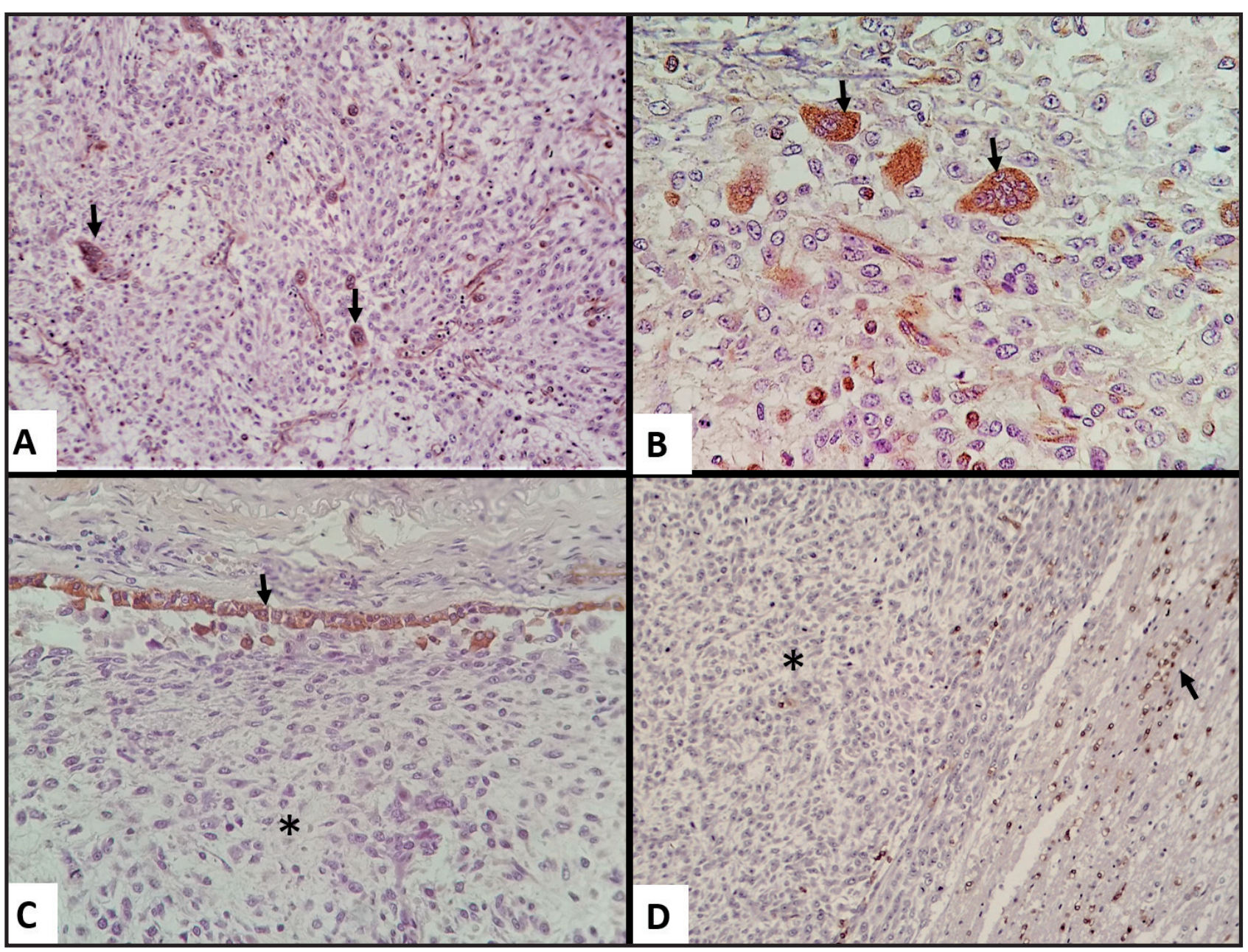

Figure 3. Immunohistochemical analysis of canine extraskeletal osteosarcoma. A- Mediastinal mass. Positive immunostaining of neoplastic cells for vimentin (arrows) [4x]. B- Mediastinal mass. Giant osteoclast cells with Ki67 immunostaining (arrows) [40x]. C- Lung. Cytokeratin-positive for bronchial epithelium (arrow) and negative for neoplastic cells $\left(^{*}\right)$ [10x]. D- Brain. Positive immunostaining of nerve cells for S100 Protein (arrow) and negative for neoplasm $(*)[4 \mathrm{x}]$

In dogs, EOS occurs mainly in the mammary glands, digestive system, liver, spleen, and subcutaneous tissue [9], whereas in humans, in the lower extremities. $[10,13]$ and in cats, the orbit, liver, duodenum, and subcutaneous tissue $[1,5,7,15]$. Furthermore, the mediastinal location observed in this study was described only in goats [3]. The clinical signs are nonspecific and varies with the location of the tumor. According to Langenbach et al. [9], EOS with dermal and subcutaneous locations have better prognoses than EOS with visceral locations, which is often imperceptible and leads to a late diagnosis made only during post mortem. In conclusion, we report a case of primary EOS with a mediastinal location in dogs. Necropsy, histopathological examination, and IHC were essential to establish the diagnosis of this OS variant.

\section{MANUFACTURERS}

${ }^{1}$ Produtos Citológicos Soldan Ltda. Porto Alegre, RS, Brazil. ${ }^{2}$ Easyway Comercio e Serviços em Informática Ltda. São Bernardo do Campo, SP, Brazil.

${ }^{3}$ Laboratório de Histoquímica do LRD/FV/UFPel. Capão do Leão, RS, Brazil.

${ }^{4}$ Biocare Medical, LLC. Pacheco, CA, USA.

${ }^{5}$ Merck/Sigma Aldrich Co. Saint Louis, MO, USA

Declaration of interest. The authors report no conflicts of interest. The authors alone are responsible for the content and writing of the paper. 


\section{REFERENCES}

1 Almela R., Bomhard W.V., Anson A. \& Mayer U. 2017. Subcutaneous extraskeletal osteosarcoma in a metatarsal footpad in a cat. Veterinary Dermatology. 28: 524-e129. DOI: 10.1111/vde.12461

2 Araújo A.C.P., Gaiga L.H., Seitz A.L. \& Driemeier D. 2006. Osteossarcoma extra-esquelético primário testicular em cão criptorquida. Acta Scientiae Veterinariae. 34(2): 197-200. DOI: 10.22456/1679-9216.15269

3 Braun U., Schwarzwald C.C., Forster E., Becker-birck M., Borel N. \& Ohlerth S. 2011. Extraskeletal osteosarcoma of the thorax in a goat: case report. BMC Veterinary Research. 7(55): 1-4. DOI: 10.1186/1746-6148-7-55

4 Chun R. \& Lorimier L.P. 2003. Update on the biology and management of canine osteosarcoma. Veterinary Clinics: Small Animal Practice. 33: 491-516. DOI: 10.1016/s0195-5616(03)00021-4

5 Dhaliwal R.S., Johnson T.O. \& Kitchell B.E. 2003. Primary extraskeletal hepatic osteosarcoma in a cat. Journal of the American Veterinary Medical Association. 222(3): 340-342. DOI: 10.2460/javma.2003.222.340

6 Duffy D., Selmic L.E., Kendall A.R. \& Powers B.E. 2015. Outcome following treatment of soft tissue and visceral extraskeletal osteosarcoma in 33 dogs: 2008-2013. Veterinary and Comparative Oncology. 15(1): 46-54. DOI: 10.111 /vco. 12141

7 Groskopf B.S., Dubielzig R.R. \& Beaumont S.L. 2010. Orbital extraskeletal osteosarcoma following enucleation in a cat: a case report. Veterinary Ophthalmology. 13(3): 179183. DOI: 10.1111/j.1463-5224.2010.00774.x

8 Guim T.N., Cecco B.S., Laisse C.J.M., Schmitt B., Henker L.C., Vieira C.R., Driemeier D., Pavarini S.P. \& Sonne L. 2019. Epidemiological and pathologic aspects of extra-skeletal osteosarcoma in dogs. Semina: Ciências Agrárias. 40(6): 3089-3098. DOI: 10.5433/1679-0359.2019v40n6Supl2p3089

9 Langenbach A., Anderson M.A., Dambach D.M., Sorenmo K.U. \& Shofer F.D. 1998. Extraskeletal osteosarcomas in dogs: A retrospective study of 169 cases (1986-1996). Journal of the American Animal Hospital Association. 34: 113-120. DOI: $10.5326 / 15473317-34-2-113$

10 Lima J.J.G., Manzi F.R., Silva F.L. \& Zuccollotto M. 2002. Osteossarcoma extra-esquelético na região cervical - revisão da literatura e relato de caso clínico. Radiologia Brasileira. 35(5): 315-319. DOI: 10.1590/S010039842002000500014

11 Lima M.A., Rivas L.G., Grecco M.A.S. \& Drumond J.M.N. 1998. Osteossarcoma extra-esquelético primário da região frontal. Revista da Associação Médica Brasileira. 44(1): 43-46. DOI: 10.1590/S0104-42301998000100008

12 Miller M.A., Aper R.L., Fauber A., Blevins W.E. \& Ramos-Vara J.A. 2006. Extraskeletal osteosarcoma associated with retained surgical sponge in a dog. Journal of Veterinary Diagnostic Investigation. 18: 224-228. DOI: 10.1177 / 104063870601800218

13 Pelizarri J.V., Dorst D.B. \& Morais C.F. 2014. Osteossarcoma primário de glande: relato de caso.|Revista Brasileira de Oncologia Clínica. 10(38): 150-154

14 Selmic L.E, Griffin L.R., Rector M.H., Lafferty M., Pool R. \& Ehrhart N.P. 2016. Treatment of extraskeletal osteosarcoma at a previous injection site resulting in prolonged survival in $1 \mathrm{dog}$. Canadian Veterinary Journal. 57: 950-954.

15 Stimson E.L., Cook W.T., Smith M.M., Forrester S.D., Moon M.L. \& Saunders G.K. 2000. Extraskeletal osteosarcoma in the duodenum of a cat. Journal of the American Animal Hospital Association. 36: 332-336. DOI: $10.5326 / 15473317-36-4-332$

16 Thompson K.G. \& Dittmer K.E. 2017. Tumors of Bone. In: Meuten D.J. (Ed). Tumors in Domestic Animals. 5th edn. Ames: Iowa State University Press, pp.356-424. 